\title{
Nasopharyngeal carcinoma in adults: treatment results after long-term follow-up with special reference to adjuvant interferon- beta in undifferentiated carcinomas
}

\author{
Hendrik Andreas Wolff · Ralph M. W. Rödel · Bastian Gunawan · Tobias Overbeck · \\ Markus K. A. Herrmann - Steffen Hennies - Andrea Hille - Hilke Vorwerk • \\ Christoph Matthias · Clemens F. Hess · Hans Christiansen
}

Received: 16 April 2009/Accepted: 23 June 2009/Published online: 18 July 2009

(C) The Author(s) 2009. This article is published with open access at Springerlink.com

\begin{abstract}
Purpose Nasopharyngeal carcinomas (NPC) are radiosensitive, and radiotherapy is the standard curative treatment. Furthermore, it has been shown that combined radiochemotherapy improves prognosis in locally advanced stages. Further encouraging results have been obtained with adjuvant interferon-beta after primary radio(chemo)therapy in childhood undifferentiated NPC. Aim of the present study was to evaluate the treatment results after long-term follow-up after radio(chemo)therapy for adult NPC with special reference to patients with undifferentiated carcinomas treated with adjuvant interferon-beta.

Patients and methods From 02/1992 to 07/2008, 26 adult patients with NPC without distant metastases were treated (17 squamous cell carcinomas, 9 undifferentiated carcinomas). The treatment concepts changed over the years: 13 patients were treated with radiotherapy alone, 13 patients
\end{abstract}

H. A. Wolff $(\bowtie) \cdot$ M. K. A. Herrmann - S. Hennies - A. Hille

H. Vorwerk - C. F. Hess · H. Christiansen

Department of Radiotherapy and Radiooncology,

Universitätsmedizin Göttingen, Robert-Koch-Strasse 40,

37075 Göttingen, Germany

e-mail: hendrik.wolff@med.uni-goettingen.de;

drhawolff@googlemail.com

R. M. W. Rödel · C. Matthias

Department of Otolaryngology, Universitätsmedizin Göttingen, Göttingen, Germany

B. Gunawan

Department of Pathology, Universitätsmedizin Göttingen, Göttingen, Germany

T. Overbeck

Department of Haematology and Oncology, Universitätsmedizin Göttingen, Göttingen, Germany received combined radiochemotherapy. Additionally, six patients with undifferentiated carcinomas were treated with adjuvant interferon-beta after radiochemotherapy for 6 months.

Results After a median follow-up of 96 months, 17 patients remain alive. Collectively, our 5-year overallsurvival and loco-regional control rates were $74 \%$ (radiochemotherapy $81 \%$, radiotherapy alone $68.5 \%$ ) and $87 \%$ (radiochemotherapy $100 \%$, radiotherapy alone $72.7 \%$ ), respectively. All treatment regimens used were feasible; especially, adjuvant interferon-beta was applied as provided without high grade toxicity. All patients with undifferentiated carcinomas treated with adjuvant interferon-beta stayed alive until the end of the follow-up.

Conclusion In summary, our data affirm that NPC in adults are curable by primary radio(chemo)therapy. Furthermore, our data indicate that adjuvant interferon-beta application in undifferentiated NPC in adults is feasible and shows promising results. Further prospective clinical trials are needed to finally establish adjuvant interferon beta in curative treatment of adult NPC.

Keywords Nasopharyngeal carcinoma - Interferon-beta . Radiochemotherapy · EBV

\section{Introduction}

The nasopharyngeal carcinoma (NPC) evolves from the epithelial cells in the nasopharynx (Jeyakumar et al. 2006). A distinction is drawn between three different histological subgroups: keratinizing squamous cell carcinoma, squamous cell carcinoma without keratinizing, and undifferentiated lymphoepithelial carcinoma (Brennan 2006). Pathogenesis of the undifferentiated carcinoma is highly 
associated with prior or acute infection with the EbsteinBarr virus (Chu et al. 2008). In some areas in South China, the incidence of NPC is about 80 of 100,000 people and NPC is a disease of the adult. Interestingly, in Western civilisation the incidence with 1 of 100,000 is much lower, but one-third of these patients are children (Licitra 2003). $70 \%$ of patients with NPC have to be classified in locally advanced stages UICC III/IVA/B at the point of diagnosis (Brennan 2006; Jeyakumar et al. 2006). Because of the tumour location in the nasopharynx with possible infiltration in the base of the skull, a complete tumour resection in curative intent is difficult in many cases. Because of a known distinctive sensitivity of nasopharyngeal carcinomas in radiotherapy, irradiation is recommended in the curative treatment for NPC's in the first line (Lee et al. 1993), and especially undifferentiated NPC should not be operated in principle. Thereby, radiotherapy alone was gold standard in curative treatment of NPC until the early 1990s (Song et al. 2008). Since several studies showed that in locally advanced carcinomas the combination of radioand chemotherapy (neoadjuvant and/or concomitant) resulted in better treatment outcome than irradiation alone (Baujat et al. 2006; Huncharek and Kupelnick 2002; Langendijk et al. 2004; Yarney et al. 2008), the combination of radio- and chemotherapy became standard procedure in the curative treatment of locally advanced (UICC stages III/IVA/B) NPC's in the late 1990s. However, the optimum chemotherapy regimen for the neoadjuvant as well as the concomitant chemotherapy has not been defined yet. Most of the reported schedules are cisplatin-based, sometimes as monotherapy, sometimes in combination with other agents like 5-FU or others (Chen et al. 2008; M'Rabti et al. 2006; Ma and Chan 2005).

Another approach in the treatment of undifferentiated NPC besides radio(chemo)therapy is an immunotherapy with interferon-beta. First, it was used in the recurrent/ metastatic situation showing a good tumour response (Dimery et al. 1989; Mahjoubi et al. 1993; Treuner et al. 1980). Because of the promising results of these reports, Mertens et al. (1997) included an adjuvant immunotherapy with interferon-beta application for 6 months after radiochemotherapy in children treated in curative intent with radio- (UICC stage I/II) or radiochemotherapy (UICC stage III/IV) in the NPC-91-GPOH trial (Nasopharynxkarzinom91-Gesellschaft für Pädiatrische Onkologie und Hämatologie) (Mertens et al. 1997, 2005). In this protocol, 59 children were treated as follows. One stage II patient received irradiation as primary therapy. The other 58 patients received three courses of neoadjuvant chemotherapy with methotrexate, cisplatin, and 5-FU followed by radiotherapy. After irradiation, all patients were treated with interferon-beta for 6 months. In summary, all patients showed excellent local-regional control and overall survival rates of 91 and $95 \%$ after 9 years, respectively (Mertens et al. 2005). Based on these results, a consecutive study for undifferentiated NPC in children started in 2003 (NPC-2003-GPOH; Nasopharynxkarzinom-2003-Gesellschaft für Pädiatrische Onkologie und Hämatologie) and is recruiting until today. In this protocol, low-risk patients (stage I or II) receive radiotherapy alone followed by intravenous interferon-beta for 6 months. Patients stage III/ IVA/B receive three courses of neoadjuvant chemotherapy with cisplatin, folinic acid, and 5-FU followed by concomitant radiochemotherapy with two courses of cisplatin and adjuvant interferon-beta for 6 months.

Because of the encouraging results of the GPOH trials investigating adjuvant interferon-beta in childhood NPC treated with primary radiochemotherapy, we started to treat adult patients with undifferentiated NPC according to the GPOH-protocols with neoadjuvant chemotherapy, followed by radio(chemo)therapy and adjuvant interferonbeta at our department in 2001.

Aim of the present study was to analyse the outcome of NPCs in adult patients during the last 17 years at our institution with special regard to adjuvant interferon-beta in undifferentiated carcinomas. Our data show in accordance with the literature that adult patients with NPC can be cured with radio(chemo)therapy alone without surgery. Besides, all patients with undifferentiated carcinomas treated with adjuvant interferon-beta according to the GPOH-protocols are still alive. Based on the results of the GPOH-studies in children and the present work, further prospective trials are needed to establish the role of interferon-beta in the curative treatment of adult NPC.

\section{Patients and methods}

\section{Patients}

Between February 1992 and July 2008, 26 adult patients with carcinoma of the nasopharynx without distant metastases were treated at our department in curative intent. Patients were 21 males and 5 females. Patients' age ranged from 28 to 81 years (median 60 years). Disease was staged according to the Union Internationale Contre le Cancer/American Joint Committee on Cancer (UICC/ AJCC) criteria (Sobin and Wittekind 2002).

Two patients were in stage II, nine patients were in stage III, and 15 patients were in stage IV. Thereby, in 2 patients the primary tumour was staged as T1, in 6 patients as T2, in 5 patients as T3, and in 13 patients as T4. In summary, 20 patients presented with positive cervical lymph nodes (1 patient N1, 16 patients N2, and 3 patients N3). Tumours were histologically determined as squamous cell carcinoma with keratinisation in 4 patients $(15 \%)$, as squamous cell 
Table 1 Pre-treatment characteristics of patients entered in the study

\begin{tabular}{|c|c|}
\hline Characteristic & No. of patients $(\%)$ \\
\hline \multicolumn{2}{|l|}{ Gender } \\
\hline Male & $21(81)$ \\
\hline Female & $5(19)$ \\
\hline \multicolumn{2}{|l|}{ UICC stage } \\
\hline II & $2(8)$ \\
\hline III & $9(34)$ \\
\hline IV & $15(58)$ \\
\hline \multicolumn{2}{|l|}{ T-Status } \\
\hline 1 & $2(8)$ \\
\hline 2 & $6(23)$ \\
\hline 3 & $5(19)$ \\
\hline 4 & $13(50)$ \\
\hline \multicolumn{2}{|l|}{ N-status } \\
\hline 0 & $6(23)$ \\
\hline 1 & $1(4)$ \\
\hline 2 & $16(62)$ \\
\hline 3 & $3(11)$ \\
\hline \multicolumn{2}{|c|}{ Histologic grade } \\
\hline 2 & $16(62)$ \\
\hline 3 & $10(38)$ \\
\hline \multicolumn{2}{|c|}{ EBV-Status in tumour } \\
\hline Positive & $17(65)$ \\
\hline Negative & $6(23)$ \\
\hline Not known & $3(12)$ \\
\hline \multicolumn{2}{|c|}{ Interferon therapy } \\
\hline Yes & $6(23)$ \\
\hline No & $20(77)$ \\
\hline \multicolumn{2}{|c|}{ Concomitant chemotherapy } \\
\hline Yes & $13(50)$ \\
\hline No & $13(50)$ \\
\hline
\end{tabular}

carcinoma without keratinisation in 13 patients $(50 \%)$ and as undifferentiated carcinoma in 9 patients (35\%). 16 patients showed histological grade 2 and ten patients showed grade 3. EBV-status in tumour biopsies before radio(chemo)therapy was determined as follows: 17 patients were EBV positive, six negative, and in three patients, status was missing because it was not determined in the early 1990s, and there were no available histologicalblocs for retrospective analysis. Patient characteristics were summarised in Table 1.

\section{Pre-treatment examinations}

Initial examinations before treatment included medical history, clinical ENT (ear-nose-throat) examination (magnifying laryngoscopy, upper bronchoscopy, esophagoscopy, ear-nose-throat endoscopy) with biopsies in potential mucosal primary sites, complete blood counts, biochemical analysis, electrocardiogram, chest X-rays, abdominal ultrasound, and CT scans of the thorax and the head and neck with contrast medium. Whenever achievable a MRI scan of the head and neck with contrast medium was carried out. Pre-treatment characteristics of patients entered in study are concluded in Table 1.

Treatment

In summary, due to changes in treatment protocols and technical developments over the years, there are differences in cumulative dose, treatment techniques, and accompanying therapies (chemotherapy, interferon-beta). Details are summarised in Table 2.

Treatment monitoring and follow-up

Toxicity was monitored weekly during radio(chemo)therapy and every second week following therapy until disappearance of acute side effects. Subsequently, chronic toxicity was monitored at least yearly for the first 5 years after radio(chemo)therapy. Side effects were classified according to the CTC score for acute (Cox et al. 1995; Trotti et al. 2000) and according to the LENT scoring system for chronic side effects (Hendry et al. 2006; Rubin et al. 1995).

After radiochemotherapy, remission was evaluated by clinical ENT-examination (ear-nose-throat endoscopy, magnifying laryngoscopy, whenever necessary upper bronchoscopy, and esophagoscopy) and a computed tomography with contrast medium. Complete remission was defined as the complete regression of all tumour manifestations. Afterwards, patients underwent quarterly clinical ENTexamination, complete blood counts, biochemical analysis, chest X-rays, abdominal ultrasound or a computed tomography of the head and neck, if necessary. Biopsies were taken from suspect findings to receive histological confirmation of tumour growth.

\section{Statistics}

Survival probabilities were calculated from the day of histological diagnosis. The Kaplan-Meier product-limit method was used to determine overall survival and locoregional control. Loco-regional control was defined as the absence of local or regional recurrence or progression. The possible impact of chemotherapy or EBV-status on prognosis was estimated by univariate analysis (log-rank test). Statistical analyses were generated with the programme STATISTICA for windows version 6.1 [StatSoft, Inc. (2002)]. 


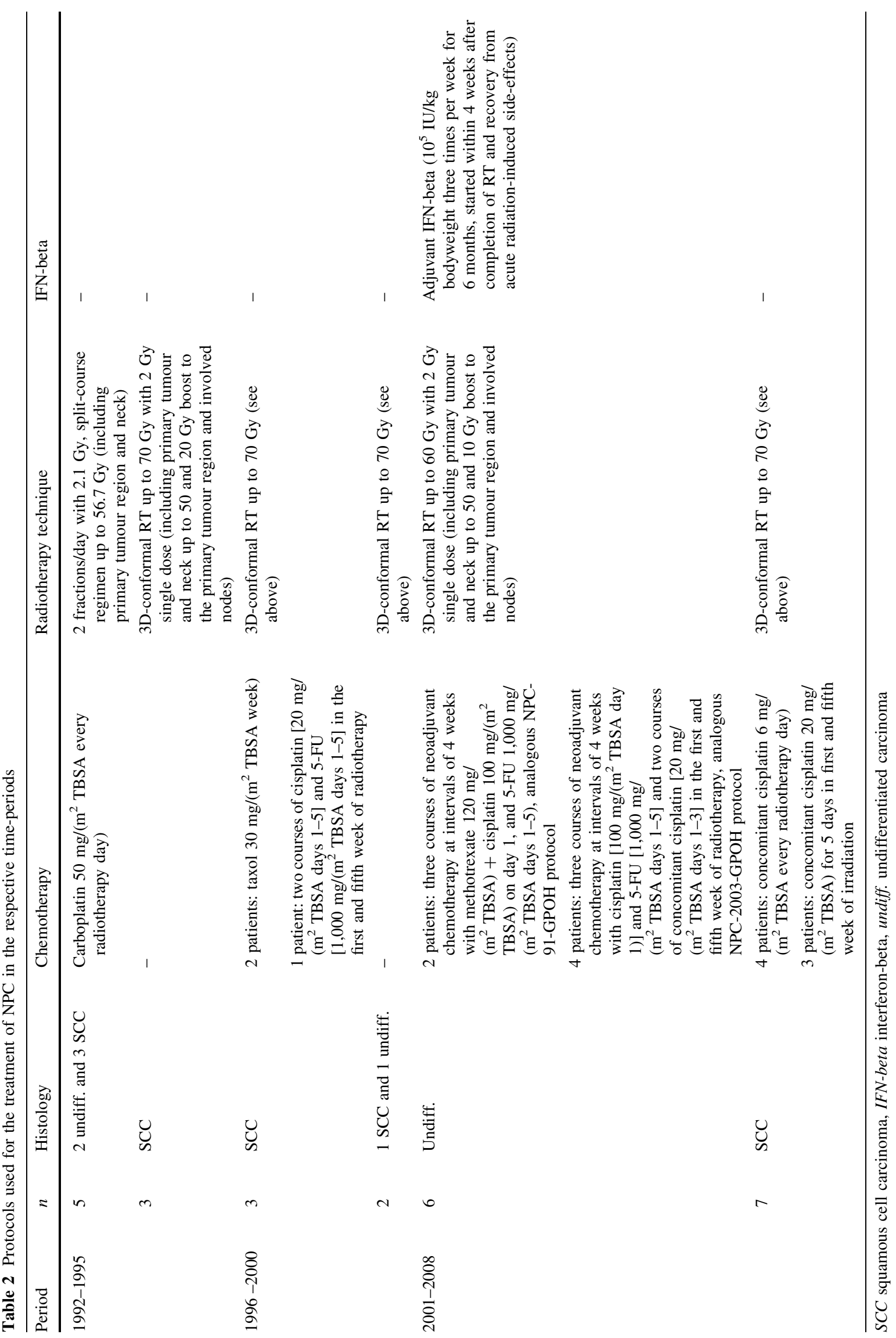




\section{Results}

After a median follow-up duration of 96 months (range 9198 months), 17 patients (65\%) remained alive. Death has occurred in nine patients $(35 \%)$; while four of these died from primary tumour, five died from intercurrent disease [one-second primary (intracranial neuroblastoma), one pulmonary embolism, one heart attack, and two not known]. Collectively, the 5-year overall survival rate was $74 \%$ (life table analysis is shown in Fig. 1). Notably, all six patients treated according to the GPOH protocols with adjuvant interferon-beta are still alive until the end of the follow-up.

Loco-regional relapse occurred in four patients (three local, one regional); median time to relapse was 22 months (range 6.4-36.8). Collectively, the 5-year loco-regional control rate was $87 \%$. One of the patients with locoregional relapse was treated according to the NPC-91$\mathrm{GPOH}$ protocol. In this patient, local relapse after 36.8 months was treated with salvage chemotherapy because of inoperability in the year 2005. This patient was still alive at the end of the follow-up without another relapse after complete remission through salvage chemotherapy. The three other patients with loco-regional relapse were squamous cell carcinomas and treated with concomitant radiochemotherapy. In the first patient, local relapse after 3 months was treated with salvage chemotherapy. This patient died 6.4 months after salvage treatment because of additional cervical metastases and general constitution. In the second patient, radiochemotherapy after macroscopic complete tumour resection was stopped on demand of the patient because of severe acute side effects after $28.8 \mathrm{~Gy}$ and one chemotherapy course. Local relapse occurred 19 months after radiochemotherapy. As salvage

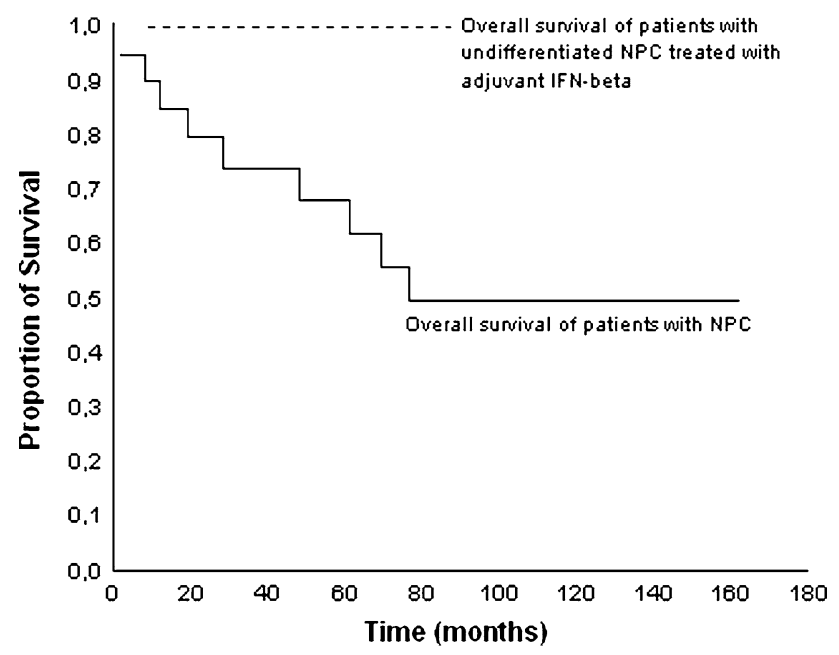

Fig. 1 Kaplan-Meier plot of overall survival for all patients, and for patients with undifferentiated NPC treated with adjuvant IFN-beta, calculated from the time of histopathological diagnosis

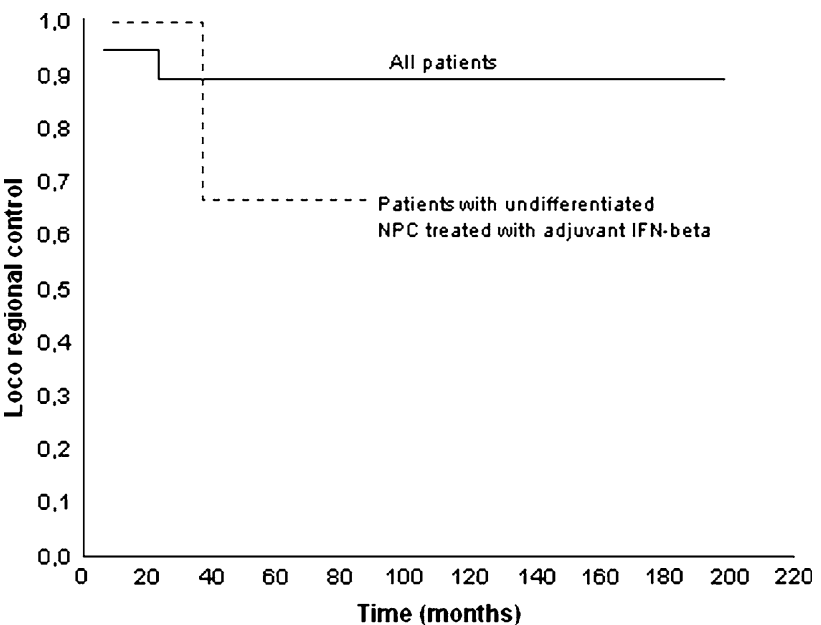

Fig. 2 Kaplan-Meier plot of loco-regional control for all patients, and for patients with undifferentiated NPC treated with adjuvant IFNbeta, calculated from the time of histopathological diagnosis

therapy, this patient underwent surgery and stayed alive until the end of the follow-up. Regional relapse after 6.4 months in third patient was treated with salvage chemotherapy. This patient died 2 months after the salvage treatment because of the general constitution (loco-regional control analysis is shown in Fig. 2).

Distant metastases occurred in two patients (one pulmonary and one mediastinal). In one patient, a secondary malignant tumour in the form of an intracranial neuroblastoma was recorded in 2004 after treatment of her NPC in 1995. After chemotherapy this patient stayed alive until the end of the follow-up without another relapse of the neuroblastoma or the NPC.

Subgroup analyses concerning chemotherapy showed better overall survival and loco-regional control rates for radio(chemo)therapy compared to radiotherapy alone [81 vs. $68.5 \%(P=0.54)$, and 100 vs. $72.7 \%(P=0.072)$, respectively]. However, the differences were not statistically significant; this may be due to the small sample size. Similarly, the EBV-status in the tumour biopsies before radio(chemo)therapy had no impact on prognosis.

\section{Toxicity}

In summary, therapy was well tolerated. There were no treatment-related deaths and no grade 4 toxicities. Grade 3 mucositis/dysphagia was seen in six patients. In an additional patient, grade 3 mucositis and skin reaction occurred. Sole haematological toxicity in form of leukopenia $\geq$ grade 3 appeared in two patients. In another two patients mucositis/dysphagia and haematological toxicity $\geq$ grade 3 (leukopenia and anaemia or leukopenia alone) was observed. Three of these patients received a concomitant radiochemotherapy; the other one was treated with irradiation alone. 
Thus, toxicity-related changes of the therapy schedule were only infrequently necessary [one patient did not receive the second of planned two courses cisplatin, one patient paused 7 days during a 5-FU and cisplatin chemotherapy, and one patient missed two infusions of cisplatin $6 \mathrm{mg} /$ $\left(\mathrm{m}^{2}\right.$ TBSA day)]. Because of severe side effects (mucositis and dysphagia), radiochemotherapy after macroscopic complete tumour resection was stopped on demand of the patient because of severe acute side effects after $28.8 \mathrm{~Gy}$, and one chemotherapy course (see above), in another patient, the boost dose was reduced from 20 to $14 \mathrm{~Gy}$ because of the dose at the organs at risk. In the six patients treated with neoadjuvant chemotherapy according to the GPOH-protocols, no side effects grade 2 or higher were observed (one patient grade 1 anaemia and leukopenia only). Adjuvant interferon-beta therapy was well tolerated and could be applied regularly by all six treated patients. Four patients developed fever during first or second application, but adapted on the therapy in following courses without any further serious side effects. Late toxicity graded $\geq 2$ was recorded in ten patients (loss of taste: 4 patients; loss of taste and xerostomia: three patients; xerostomia alone: two patients; xerostomia, fibrosis and lymph oedema: one patient, fibrosis did not significantly impair quality of life during follow-up). One of these patients was treated with neoadjuvant chemotherapy, six with concomitant radiochemotherapy and three with irradiation alone. There was no ototoxicity assessed in our patient population.

\section{Discussion}

Our data confirm the known fact that NPC can be cured by radio(chemo)therapy and has a significant better prognosis compared to the other squamous cell head and neck cancer entities (oral cavity, oropharynx, hypopharynx, larynx). Thereby, our disease overall survival ( $74 \%$ after 5 years), and loco-regional control rates (87\% after 5 years) are comparable to the literature (Table 3). Furthermore, to our knowledge, we are the first in literature to report the treatment of adult NPC patients with radiochemotherapy followed by adjuvant administration of interferon-beta according to the GPOH protocols for childhood NPC [NPC-1991 GPOH (Mertens et al. 2005; Mertens et al. 1997), NPC-2003 GPOH]. Our experiences show that this regime is feasible without unacceptable toxicity in adult patients. Furthermore, the fact that all our patients treated with this regime are still alive at the end of our analysis is encouraging and demand further prospective studies in this field.

However, the optimal radiochemotherapy schedule for NPC has not been defined yet. Besides good treatment results obtained by concomitant radio(chemo)therapy, local relapse is still a major problem (Daoud and Frikha 2001; Lu 2004; O'Sullivan 2007; Yarney et al. 2008). One possibility to improve LRC, and thus OS, is dose escalation of radiotherapy, and several authors propagate this in radiotherapy for NPC (Lauve et al. 2004; Lu et al. 2004a).

Table 3 Overall Survival and Loco Regional Control of different radio(chemo)therapy regimens for treatment of Nasopharyngeal Carcinoma

\begin{tabular}{|c|c|c|c|c|c|}
\hline Study & Patients (n) & Treatment & $\begin{array}{l}\text { RT-dose } \\
\text { (Gy) }\end{array}$ & $\begin{array}{l}\text { Loco Regional } \\
\text { Control }\end{array}$ & Overall Survival \\
\hline Present study & 26 & $\mathrm{R}(\mathrm{C}) \mathrm{T}$ & $56-70.4$ & 5 years: $87 \%$ & $\begin{array}{l}5 \text { years: } 74 \% \\
\text { Sequent CT, R(C)T and IF } \\
\text { (for undifferentiated NPC) } \\
5 \text { years: } 100 \%\end{array}$ \\
\hline NPC-91-GPOH (Mertens et al. 2005) & 59 & Sequent $\mathrm{CT}, \mathrm{RT}$ and IF & 59.4 & 9 years: $91 \%$ & 9 years: $95 \%$ \\
\hline Chua 1998 (Chua et al. 1998) & 335 & $\begin{array}{l}\mathrm{RT} \\
\mathrm{C}+\mathrm{RT}\end{array}$ & $66-74$ & $\begin{array}{l}5 \text { years: } 71 \% \\
5 \text { years: } 78 \%\end{array}$ & $\begin{array}{l}5 \text { years: } 42 \% \\
5 \text { years: } 48 \%\end{array}$ \\
\hline Ma 2001 (Ma et al. 2001) & 456 & $\begin{array}{l}\mathrm{RT} \\
\mathrm{C}+\mathrm{RT}\end{array}$ & $68-72$ & $\begin{array}{l}5 \text { years: } 49 \% \\
5 \text { years: } 59 \%\end{array}$ & $\begin{array}{l}5 \text { years: } 56 \% \\
5 \text { years: } 63 \%\end{array}$ \\
\hline Dimery 1993 (Dimery et al. 1993) & 47 & $\mathrm{C}+\mathrm{RT}$ & $68-72$ & 6 years: $73 \%$ & 6 years: $67 \%$ \\
\hline Zhang 2005 (Zhang et al. 2005) & 115 & $\begin{array}{l}\mathrm{RT} \\
\mathrm{RCT}\end{array}$ & $70-74$ & $\begin{array}{l}2 \text { years: } 83 \% \\
2 \text { years: } 96 \%\end{array}$ & $\begin{array}{l}2 \text { years: } 77 \% \\
2 \text { years: } 100 \%\end{array}$ \\
\hline Chan 2005 (Chan et al. 2005) & 350 & $\begin{array}{l}\text { RT } \\
\text { RCT }\end{array}$ & $66-76$ & $\begin{array}{l}5 \text { years: } 52 \% \\
5 \text { years: } 62 \%\end{array}$ & $\begin{array}{l}5 \text { years: } 59 \% \\
5 \text { years: } 72 \%\end{array}$ \\
\hline Wee 2005 (Wee et al. 2005) & 189 & $\begin{array}{l}\text { RT } \\
\text { RCT }\end{array}$ & 70 & $\begin{array}{l}3 \text { years: } 53 \% \\
3 \text { years: } 72 \%\end{array}$ & $\begin{array}{l}3 \text { years: } 65 \% \\
3 \text { years: } 80 \%\end{array}$ \\
\hline
\end{tabular}

$R T$ radiotherapy; $C T$ chemotherapy; $I F$ interferon-beta, $C+R T$ neoadjuvant chemotherapy + radiotherapy; $R C T$ radiochemotherapy; $O S$ overall survival, DSS disease specific survival 
However, this is difficult to achieve in the nasopharyngeal region due to close critical organs, e.g. optical nerve, chiasm, and brainstem. Further optimisation and establishment of recent advantages in radiotherapy may help to apply higher doses, e.g. by brachytherapy (Lu et al. 2004a; Ng et al. 2005), IMRT (Lu et al. 2004b; Parliament et al. 2005), and stereotactic radiotherapy (Low et al. 2006; Wu et al. 2007).

On the other hand, in the NPC-91-GPOH study, excellent overall survival-95\% after 9 years-and disease-free survival-91\% after 9 years, respectively, could be obtained with a total radiation dose of 59.4 Gy only (Mertens et al. 2005). In the current NPC-2003-GPOH study, a further dose reduction of $54 \mathrm{~Gy}$ is intended for children with complete tumour regression after neoadjuvant chemotherapy. These encouraging results of the $\mathrm{GPOH}$ studies show that possibly in undifferentiated nasopharyngeal carcinoma a further dose escalation is not necessary when adjuvant interferon beta and neoadjuvant chemotherapy are given, and indicates that both should also be applied in adult patients, as well as in childhood NPC. This is of special importance as the lower the radiation dose the lower the risk for acute and chronic radiation-induced side effects and the higher the quality of life for the patients. The question, whether a reduction of the radiation dose while intensifying systemic therapy to reduce the risk for radiation-induced side effects without compromising tumour control is also currently under investigation in a multicenter phase III studyPaccis-RCT (Paclitaxel-Cisplatin-Radiochemotherapie)of the "Deutsche Krebshilfe" for advanced head and neck squamous cell carcinoma (oral cavity, oropharynx, hypopharynx, larynx): In this study, the standard arm includes 70.2 Gy irradiation ( 3 weeks $5 \times 2$ Gy/week and 3 weeks $2 \times 1.4 \mathrm{~Gy} /$ day, five times per week) with additional $5-\mathrm{FU}\left[600 \mathrm{mg} /\left(\mathrm{m}^{2}\right.\right.$ TBSA day $\left.)\right]$ and cisplatin $[20 \mathrm{mg} /$ $\left(\mathrm{m}^{2}\right.$ TBSA day)] for 5 days in week 1 and 5 of irradiation. In the experimental arm, radiation dose is reduced to 63.6 Gy ( 3 weeks $5 \times 2$ Gy/week and 2.5 weeks $2 \times$ $1.4 \mathrm{~Gy} /$ day, five times per week) plus intensified concomitant chemotherapy (cisplatin $20 \mathrm{mg} /\left(\mathrm{m}^{2}\right.$ TBSA day) for 5 days in week 1 and 5 ; taxol $25 \mathrm{mg} /\left(\mathrm{m}^{2}\right.$ TBSA day) on day $1,4,8,12,26,30,33$, and 37). Aim of the study is, to test, whether the reduction of the radiation dose with intensified chemotherapy results in fewer side effects without compromising tumour control.

In comparison to other tumour entities of the head and neck, the NPC is distinctively sensible to radio- and chemotherapy, and can be cured without surgery in locally advanced stages at a high percentage (Brennan 2006). One hypothesis for this fact is the frequent viral association with Ebstein-Barr virus infection which is reported to be a high frequent factor in tumour genesis in NPC. For example, Lin et al. (2004) found a plasma DNA of the EB virus in 94 of
99 patients with NPC but not in 40 healthy or cured patients. Analogue findings were reported in other studies (RaabTraub 2002; Zhou et al. 2005). Similarly, other tumour entities, like anal or cervix carcinoma are also well known to be virus associated and radio(chemo)therapy sensible too (Bosch et al. 2002; Castellsague 2008; Robinson et al. 2009; Smith et al. 2007). Furthermore, it was shown that quantification of plasma EBV DNA and other serum parameters like anti-EBV antibodies even allows patient monitoring with NPC under treatment and can predict outcome and probability of recurrence (de-Vathaire et al. 1988; Guigay 2008; Lin et al. 2004). Unfortunately, we could not show this in our analysis due to the fact that EBV parameters despite the initial EBV-status in the tumour were not collected in our patients. However, we now started to monitor EBV DNA and serum parameters in all patients treated with NPC at our department now and in the future. Through this, further analyses including bio-monitoring and controls in the course of treatment will be possible.

In summary, our data affirm that NPC in adults are curable by primary radio(chemo)therapy. Furthermore, our data indicate that adjuvant interferon-beta application in undifferentiated NPC in adults is feasible and shows promising results. Further prospective clinical trials are needed to finally establish adjuvant interferon beta in curative treatment of adult NPC.

Open Access This article is distributed under the terms of the Creative Commons Attribution Noncommercial License which permits any noncommercial use, distribution, and reproduction in any medium, provided the original author(s) and source are credited.

\section{References}

Baujat B, Audry H, Bourhis J, Chan AT, Onat H, Chua DT, Kwong DL, Al-Sarraf M, Chi KH, Hareyama M et al (2006) Chemotherapy in locally advanced nasopharyngeal carcinoma: an individual patient data meta-analysis of eight randomized trials and 1753 patients. Int J Radiat Oncol Biol Phys 64:47-56

Bosch FX, Lorincz A, Munoz N, Meijer CJ, Shah KV (2002) The causal relation between human papillomavirus and cervical cancer. J Clin Pathol 55:244-265

Brennan B (2006) Nasopharyngeal carcinoma. Orphanet J Rare Dis $1: 23$

Castellsague X (2008) Natural history and epidemiology of HPV infection and cervical cancer. Gynecol Oncol 110:S4-S7

Chan AT, Leung SF, Ngan RK, Teo PM, Lau WH, Kwan WH, Hui EP, Yiu HY, Yeo W, Cheung FY et al (2005) Overall survival after concurrent cisplatin-radiotherapy compared with radiotherapy alone in locoregionally advanced nasopharyngeal carcinoma. J Natl Cancer Inst 97:536-539

Chen Y, Liu MZ, Liang SB, Zong JF, Mao YP, Tang LL, Guo Y, Lin AH, Zeng XF, Ma J (2008) Preliminary results of a prospective randomized trial comparing concurrent chemoradiotherapy plus adjuvant chemotherapy with radiotherapy alone in patients with locoregionally advanced nasopharyngeal carcinoma in endemic regions of china. Int J Radiat Oncol Biol Phys 71:1356-1364 
Chu EA, Wu JM, Tunkel DE, Ishman SL (2008) Nasopharyngeal carcinoma: the role of the Epstein-Barr virus. Medscape J Med 10:165

Chua DT, Sham JS, Choy D, Lorvidhaya V, Sumitsawan Y, Thongprasert S, Vootiprux V, Cheirsilpa A, Azhar T, Reksodiputro AH (1998) Preliminary report of the Asian-Oceanian Clinical Oncology Association randomized trial comparing cisplatin and epirubicin followed by radiotherapy versus radiotherapy alone in the treatment of patients with locoregionally advanced nasopharyngeal carcinoma Asian-Oceanian Clinical Oncology Association Nasopharynx Cancer Study Group. Cancer 83:2270-2283

Cox JD, Stetz J, Pajak TF (1995) Toxicity criteria of the Radiation Therapy Oncology Group (RTOG) and the European Organization for Research and Treatment of Cancer (EORTC). Int J Radiat Oncol Biol Phys 31:1341-1346

Daoud J, Frikha M (2001) Carcinoma of the nasopharynx. Radiotherapy modalities and combined radiotherapy and chemotherapy: state of the art and perspectives. Cancer Radiother 5(Suppl 1): $195 \mathrm{~s}-200 \mathrm{~s}$

de-Vathaire F, Sancho-Garnier H, de-The H, Pieddeloup C, Schwaab G, Ho JH, Ellouz R, Micheau C, Cammoun M, Cachin Y et al (1988) Prognostic value of EBV markers in the clinical management of nasopharyngeal carcinoma (NPC): a multicenter follow-up study. Int J Cancer 42:176-181

Dimery IW, Jacobs C, Tseng A Jr, Saks S, Pearson G, Hong WK, Gutterman JU (1989) Recombinant interferon-gamma in the treatment of recurrent nasopharyngeal carcinoma. J Biol Response Mod 8:221-226

Dimery IW, Peters LJ, Goepfert H, Morrison WH, Byers RM, Guillory C, McCarthy K, Weber RS, Hong WK (1993) Effectiveness of combined induction chemotherapy and radiotherapy in advanced nasopharyngeal carcinoma. J Clin Oncol 11:1919-1928

Guigay J (2008) Advances in nasopharyngeal carcinoma. Curr Opin Oncol 20:264-269

Hendry JH, Jeremic B, Zubizarreta EH (2006) Normal tissue complications after radiation therapy. Rev Panam Salud Publica 20:151-160

Huncharek M, Kupelnick B (2002) Combined chemoradiation versus radiation therapy alone in locally advanced nasopharyngeal carcinoma: results of a meta-analysis of 1,528 patients from six randomized trials. Am J Clin Oncol 25:219-223

Jeyakumar A, Brickman TM, Doerr T (2006) Review of nasopharyngeal carcinoma. Ear Nose Throat J 85:168-170, 172-163, 184

Langendijk JA, Leemans CR, Buter J, Berkhof J, Slotman BJ (2004) The additional value of chemotherapy to radiotherapy in locally advanced nasopharyngeal carcinoma: a meta-analysis of the published literature. J Clin Oncol 22:4604-4612

Lauve A, Morris M, Schmidt-Ullrich R, Wu Q, Mohan R, Abayomi O, Buck D, Holdford D, Dawson K, Dinardo L, Reiter E (2004) Simultaneous integrated boost intensity-modulated radiotherapy for locally advanced head-and-neck squamous cell carcinomas: II. Clinical results. Int J Radiat Oncol Biol Phys 60:374-387

Lee AW, Law SC, Foo W, Poon YF, Chan DK, O SK, Tung SY, Cheung FK, Thaw M, Ho JH (1993) Nasopharyngeal carcinoma: local control by megavoltage irradiation. Br J Radiol 66:528-536

Licitra L (2003) Chemoradiation therapy in locally advanced nasopharyngeal cancer: which kind of cooperation? Ann Oncol 14:508-509

Lin JC, Wang WY, Chen KY, Wei YH, Liang WM, Jan JS, Jiang RS (2004) Quantification of plasma Epstein-Barr virus DNA in patients with advanced nasopharyngeal carcinoma. N Engl $\mathrm{J}$ Med 350:2461-2470
Low JS, Chua ET, Gao F, Wee JT (2006) Stereotactic radiosurgery plus intracavitary irradiation in the salvage of nasopharyngeal carcinoma. Head Neck 28:321-329

Lu TX (2004) Advance in diagnosis and management of local recurrent nasopharyngeal carcinoma. Ai Zheng 23:230-234

Lu JJ, Shakespeare TP, Tan LK, Goh BC, Cooper JS (2004a) Adjuvant fractionated high-dose-rate intracavitary brachytherapy after external beam radiotherapy in $\mathrm{Tl}$ and $\mathrm{T} 2$ nasopharyngeal carcinoma. Head Neck 26:389-395

Lu TX, Mai WY, Teh BS, Zhao C, Han F, Huang Y, Deng XW, Lu LX, Huang SM, Zeng ZF et al (2004b) Initial experience using intensity-modulated radiotherapy for recurrent nasopharyngeal carcinoma. Int J Radiat Oncol Biol Phys 58:682-687

M'Rabti H, Sbiti Y, Afqir S, Boutayeb S, Errihani H (2006) Chemotherapy in nasopharyngeal carcinoma. Ann Otolaryngol Chir Cervicofac 123:59-64

Ma BB, Chan AT (2005) Recent perspectives in the role of chemotherapy in the management of advanced nasopharyngeal carcinoma. Cancer 103:22-31

Ma J, Mai HQ, Hong MH, Min HQ, Mao ZD, Cui NJ, Lu TX, Mo HY (2001) Results of a prospective randomized trial comparing neoadjuvant chemotherapy plus radiotherapy with radiotherapy alone in patients with locoregionally advanced nasopharyngeal carcinoma. J Clin Oncol 19:1350-1357

Mahjoubi R, Bachouchi M, Munck JN, Busson P, Gasmi J, Azli N, Brandely M, Trusz T, Cvitkovic E, Armand JP (1993) Phase II trial of recombinant interferon gamma in refractory undifferentiated carcinoma of the nasopharynx. Head Neck 15:115-118

Mertens R, Granzen B, Lassay L, Gademann G, Hess CF, Heimann G (1997) Nasopharyngeal carcinoma in childhood and adolescence: concept and preliminary results of the cooperative GPOH study NPC-91. Gesellschaft fur Padiatrische Onkologie und Hamatologie. Cancer 80:951-959

Mertens R, Granzen B, Lassay L, Bucsky P, Hundgen M, Stetter G, Heimann G, Weiss C, Hess CF, Gademann G (2005) Treatment of nasopharyngeal carcinoma in children and adolescents: definitive results of a multicenter study (NPC-91-GPOH). Cancer 104:1083-1089

Ng T, Richards GM, Emery RS, Ho G, Yung R, Cheng A, Berson AM (2005) Customized conformal high-dose-rate brachytherapy boost for limited-volume nasopharyngeal cancer. Int J Radiat Oncol Biol Phys 61:754-761

O'Sullivan B (2007) Nasopharynx cancer: therapeutic value of chemoradiotherapy. Int J Radiat Oncol Biol Phys 69:S118-S121

Parliament M, Alidrisi M, Munroe M, Wolfaardt J, Scrimger R, Thompson H, Field C, Kurien E, Hanson J (2005) Implications of radiation dosimetry of the mandible in patients with carcinomas of the oral cavity and nasopharynx treated with intensity modulated radiation therapy. Int J Oral Maxillofac Surg 34: $114-121$

Raab-Traub N (2002) Epstein-Barr virus in the pathogenesis of NPC. Semin Cancer Biol 12:431-441

Robinson D, Coupland V, Moller H (2009) An analysis of temporal and generational trends in the incidence of anal and other HPV-related cancers in Southeast England. Br J Cancer 100: $527-531$

Rubin P, Constine LS 3rd, Fajardo LF, Phillips TL, Wasserman TH, EORTC Late Effects Working Group (1995) Overview of late effects normal tissues (LENT) scoring system. Radiother Oncol 35:9-10

Smith JS, Lindsay L, Hoots B, Keys J, Franceschi S, Winer R, Clifford GM (2007) Human papillomavirus type distribution in invasive cervical cancer and high-grade cervical lesions: a metaanalysis update. Int $\mathrm{J}$ Cancer 121:621-632

Sobin LH, Wittekind C (2002) TNM classification of malignant tumours, 6th edn edn. Wiley-Liss, New York 
Song CH, Wu HG, Heo DS, Kim KH, Sung MW, Park CI (2008) Treatment outcomes for radiotherapy alone are comparable with neoadjuvant chemotherapy followed by radiotherapy in earlystage nasopharyngeal carcinoma. Laryngoscope 118:663-670

Treuner J, Niethammer D, Dannecker G, Hagmann R, Neef V, Hofschneider PH (1980) Successful treatment of nasopharyngeal carcinoma with interferon. Lancet 1:817-818

Trotti A, Byhardt R, Stetz J, Gwede C, Corn B, Fu K, Gunderson L, McCormick B, Morrisintegral M, Rich T et al (2000) Common toxicity criteria: version 2.0. An improved reference for grading the acute effects of cancer treatment: impact on radiotherapy. Int J Radiat Oncol Biol Phys 47:13-47

Wee J, Tan EH, Tai BC, Wong HB, Leong SS, Tan T, Chua ET, Yang E, Lee KM, Fong KW et al (2005) Randomized trial of radiotherapy versus concurrent chemoradiotherapy followed by adjuvant chemotherapy in patients with American Joint Committee on Cancer/International Union against cancer stage III and IV nasopharyngeal cancer of the endemic variety. J Clin Oncol 23:6730-6738
Wu SX, Chua DT, Deng ML, Zhao C, Li FY, Sham JS, Wang HY, Bao Y, Gao YH, Zeng ZF (2007) Outcome of fractionated stereotactic radiotherapy for 90 patients with locally persistent and recurrent nasopharyngeal carcinoma. Int J Radiat Oncol Biol Phys 69:761-769

Yarney J, Vanderpuye V, Kitcher ED (2008) Treatment outcome of locally advanced nasopharyngeal cancer with concurrent chemoradiotherapy. West Afr J Med 27:65-68

Zhang L, Zhao C, Peng PJ, Lu LX, Huang PY, Han F, Wu SX (2005) Phase III study comparing standard radiotherapy with or without weekly oxaliplatin in treatment of locoregionally advanced nasopharyngeal carcinoma: preliminary results. J Clin Oncol 23:8461-8468

Zhou L, Jiang W, Ren C, Yin Z, Feng X, Liu W, Tao Q, Yao K (2005) Frequent hypermethylation of RASSF1A and TSLC1, and high viral load of Epstein-Barr virus DNA in nasopharyngeal carcinoma and matched tumor-adjacent tissues. Neoplasia 7:809-815 